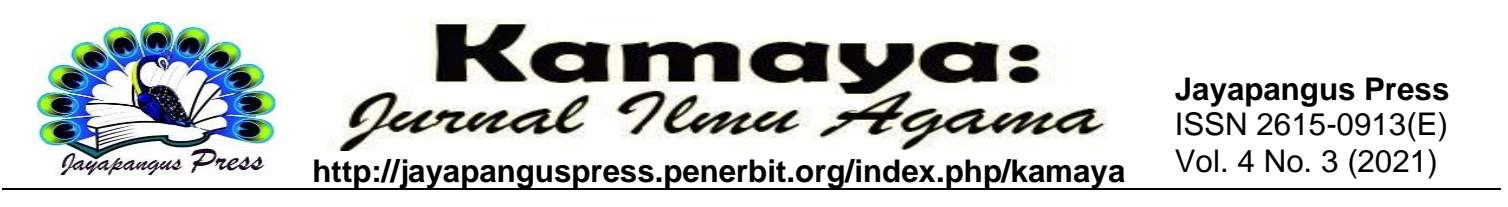

\title{
Pemujaan Dewa-Dewa Lokal Dalam Pelaksanaan Saṃskāra Di Desa Pedawa Buleleng Bali
}

\author{
Putu Maria Ratih Anggraini' ${ }^{1}$ I Nyoman Suka Ardiyasa ${ }^{2}$ \\ ${ }^{12}$ STAH N Mpu Kuturan Singaraja \\ ${ }^{1}$ mariaratihanggraini@gmail.com, ${ }^{2}$ suka.ardiyasa@gmail.com
}

\begin{tabular}{l}
\hline Keywords: \\
\hline Local Deity \\
Worship, \\
Saṃskāra, \\
Pedawa Village \\
\hline
\end{tabular}

\begin{abstract}
The worship of local gods in the implementation of Samskära in the Pedawa Village community is seen in the Sesapa spoken by Balian Desa in the implementation of the ritual. Not only local gods but worship of places and temples in Pedawa Village is also carried out. This study questions the worship of local gods that was carried out during the implementation of Samskära in Pedawa Village. The method used in this research is descriptive qualitative. Data was collected by using interview and direct observation techniques. The results of this study show that the worship of local gods in the implementation of Samskāra in Pedawa Village can be divided into 4, namely (1) worship that is specifically shown to local gods, namely worship of gods who are believed by the Pedawa people to provide salvation as Ida Pengkan Prataksu, Ida Gede Kemulan, Rai Ida. (b) special worship for places in Pedawa Village such as Gunung Sari Pedawa, In Kamulan Bingin, Telaga Waja Pengampelan and other places in Pedawa Village (c) worship of holy places in Duurin Capah, namely worship of temples in the Tamblingan and Buyan Areas or known as Dalem Tamblingan Village Chess such as Ulun Danu Tamblingan Temple, Dalem Naga Loka, Sang Hyang Kangin, Dangin Capah taler ring Steaming. (d) worship of sacred places in Segara, namely the worship of the Labuan Aji Temple which is believed by the Duwuran Capah community to be a very important temple on the coast of the North Coast of Bali.
\end{abstract}

Kata Kunci:

Pemujaan Dewa

Lokal, Saṃskāra,

Desa Pedawa

\begin{tabular}{l} 
Abstrak \\
Pemujaan dewa-dewa lokal dalam pelaksanaan Samskāra pada \\
masyarakat Desa Pedawa terlihat dalam Sesapa yang \\
diucapakan oleh Balian Desa dalam pelaksanaan ritualnya. \\
Tidak hanya dewa-dewa lokal namun pemujaan terhadap \\
tempat dan pura yang ada di Desa Pedawa juga dilakukan. \\
Penelitian ini menyoal pemujaan Dewa-Dewa lokal yang \\
dilakukan pada saat pelaksaan Samskāra di Desa Pedawa. \\
Metode yang digunakan dalam penelitian ini adalah deskriptif \\
kualitatif. Pengumpulan data dilakukan dengan teknik \\
\hline
\end{tabular}


wawancara dan observasi langsung. Hasil penelitian ini menunjukan Pemujaan dewa-dewa lokal dalam pelaksanaan Samskāara di Desa Pedawa dapat dibedakan menjadikan 4 yaitu (1) pemujaan yang khusus ditunjukan untuk dewa-dewa lokal yaitu pemujaan kepada dewa-dewa yang diyakini oleh masyarakat Pedawa memberikan keselamatan seperti sebutan Ida Pengakan Prataksu, Ida Gede Kemulan, Rai Ida.(b) pemujaan khusus untuk tempat di Desa Pedawa seperti Gunung Sari Pedawa, Di Kamulan Bingin, Telaga Waja Pengempelan dan tempat lainnya di Desa Pedawa (c) pemujaan tempat suci di Duurin Capah yaitu pemujaan kepada pura pura yang ada di Kawasan Tamblingan dan Buyan atau yang dikenal dengan Catur Desa Dalem Tamblingan seperti Pura Ulun Danu Tamblingan, Dalem Naga Loka, Sang Hyang Kangin, Dangin Capah taler ring Pengukusan. (d) pemujaan tempat suci di Segara yaitu pemujaan Pura Labuan Aji yang diyakini oleh masyarakat Duwuran Capah sebagai Pura yang sangat penting yang ada di pesisir Pantai Utara Bali.

\section{Pendahuluan}

Agama Hindu sebagai agama tertua yang menjadi tonggak awal lahirnya agama-agama lain di dunia merupakan agama yang menerapkan konsep universal dan fleksibel dalam proses penerapan agamanya. Menurut Svami Sivānanda yang menyatakan: Hinduisme sangatlah universal, bebas, toleran, dan luwes, ini terbukti dari banyaknya sekta-sekta dan keyakinan yang berbeda-beda dalam agama Hindu. Ini semua menunjukkan kemampuan umatNya dalam memikirkan atau membayangkan Tuhan Yang Maha Esa (Titib, 1995 : 62). Dalam kefleksibelan dan keuniversalan tersebut agama Hindu tetap bersumber atau memiliki pedoman yang sama yaitu kitab suci Veda.

Secara umum agama Hindu mengenal dua konsep di dalam memahami Tuhannya, yaitu Nirguna Brahman dan Saguna Brahman. Mereka yang tinggi pengetahuan rohaninya dapat memahami Tuhan Yang Maha Esa sebagai Nirguna Brahman atau Impersonal God yaitu Tuhan yang tanpa wujud dan guna baik itu dalam pikiran maupun dalam kata-kata. Dengan kata lain, Nirguna Brahman merupakan Tuhan yang tidak bisa digambarkan dengan apa-apa dan tidak memiliki wujuh (kosong). (Donder, 2006:228). Sedangkan bagi yang pemahamannya sederhana, Tuhan Yang Maha Esa digambarkan atau di wujudkan sebagai Saguna Brahman atau Personal God yaitu Tuhan yang memiliki peribadi dan dibayangkan sebagai wujud yang agung, maha pengasih, maha besar, dan sebagainya (Titib, 1996:99). Selain itu, Saguna Brahman 
yang merupakan salah satu jalan atau cara menghayati dan meyakini Tuhan dalam berbagai aspek manifestasi-Nya, baik dalam manifestasi beliau sebagai dewa-dewa atau avatara (Donder, 2006:234), Pada umumnya umat Hindu menyembah Tuhan Yang Maha Esa yang memiliki wujud personal atau Saguna ini, dikarenakan keterbatasan alam pikiran manusia dalam memikirkan Tuhan yang Nirguna. Selain itu, masih banyak lagi sebutan nama Tuhan yang diwujudkan dalam bentuk dewa-dewi, seperti Dewa Siwa, Wisnu, Brahma, Kwera, Ludra, Iswara, Dewi Sri, Durga, Uma, Saraswati, dan masih banyak lagi yang lainnya. Melalui wujud Saguna inilah manusia menunjukkan sembah bhaktinya kehadapan Tuhan Yang Maha Esa, seperti melakukan upacaraupacara pemujaan dengan menggunakan media arca, pratima, bangunan suci (pura), dan lain sebagainya, dengan tujuan memohon anugrah kepada Tuhan, agar selalu diberikan perlindungan, kedamaian, kesejahteraan dalah hidup ini.

Pemujaan terhadap dewa-dewa lokal telah banyak dilakukan oleh para peneliti, baik yang dilakukan di Desa Pedawa maupun diluar Desa Pedawa. Salah satu penelitian yang membahas tentang pemujaan terhadap Dewa Lokal dengan menggunakan Bahasa Pedawa dilakukan oleh Mayuko Hara, seorang peneliti kebangsaan Jepang. Dalam penelitiannnya disebutkan bahwa bentuk hormat kepada para dewa yang ada di Desa Pedawa menggunakan bahasa Bali Dialek Pedawa yang menggunakan kategori Bahasa Alus Singgih. Peneliti yang lain yang juga melakukan penelitian di Desa Pedawa adalah Arik Febriani dari Universitas Udayana yang berjudul Yos Sebagai Pengintegrasian Masyarakat Desa Pedawa disebutkan bahwa masyarakat Desa Pedawa memiliki Yos atau Kelompok. Ikatan Yos tersebut terdapat dewa yang sangat dimuliakan dan dewa yang paling dekat dengan masyarakat karena dewa tersebut dipercayai sebagai dewa pelindung,dengan adanya Yos tersebut maka terbentuknya kelas sosial dalam masyarakat. Adapun

tujuannya ialah untuk mengetahui status dan peran anggota masyarakat berdasarkan Yos, dan untuk mengungkap implikasi Yos dalam struktur sosial masyarakat Desa Pedawa.hasil penelitian mengungkapkan bahwa ada 14 macam Yos. Dari beberapa hasil penelitian tersebut pemujaan terhadap Dewa-Dewa Lokal dalam pelaksanaan Samskara di Desa Pedawa belum ada yang secara mengulas lebih jauh, terlebih-lebih penyebutan nama-nama Dewa Lokal tersebut dalam kontek pelaksanaan upacara. Artikel ini akan mencoba menelaah terkait dengan pemujaan Dewa Lokal yang dilakukan oleh masyarakat Desa Pedawa yang puput oleh Balian Desa. 


\section{Metode}

Penelitian ini menggunakan metode deskriptif kualitatif. Menurut (Moleong, 2006 : 16) penelitan kualitatif bermaksud untuk memahami fenomena yang dialami sendiri oleh subjek penelitian secara holistik lalu dideskripsikan dalam bentuk paparan kebahasaan yang dapat berupa kata-kata atau teks tulis. Ada tiga langkah yang dilakukan dalam pengumpulan data penelitian ini, diantaranya dengan cara observasi sekaligus perekaman pelaksanaan ritual yang dilakukan pada Desa Bali Aga, selanjutnya adalah proses wawancara dengan Balian Desa dan tokoh-tokoh yang dianggap memahami Sesapa di Desa Bali Aga. Setelah itu barulah melakukan studi dokumen, khususnya dokumen yang terkait dengan Sesapa. Dari keseluruh proses tersebut terlebih dahulu dilakukan transkrip dari ucapan Sesapa oleh yang diungkapkan oleh Balian Desa. Transkrip inilah dijadikan data primer dalam menganalisis bentuk dan makna dari Sesapa yang digunakan oleh masyarakat Bali Aga dalam pelaksanaan ritual.

\section{Hasil dan Pembahasan}

Hindu memiliki dua konsep yakni Saguna dan Nirguna Brahman. Saguna Brahman adalah Tuhan dalam manifestasinya, Dia berwujud, memiliki aspek, atribut, dan sifat. Nirguna Brahman adalah Tuhan yang tidak termanifestasikan, kosong, tidak berwujud, tidak dapat dicapai dengan akal pikiran dan panca indra. (Titib, 2003 : 10). Makna Teologi dalam Sesapa Saṃskāra masyarakat Desa Pedawa dapat digambarkan dari penyebutan pemujaan para Dewa, Bhatara atau nama-nama tempat yang dianggap suci oleh Balian Desa dalam muput sebuah upacara. Jika dicermati makna Teologi dari pengucapan Sesapa Samskāara ini dapat dibedakan menjadi 4 (empat) yaitu (a) pemujaan untuk dewa-dewa lokal (b) pemujaan tempat di Desa Pedawa (c) pemujaan tempat suci di Duurin Capah dan (d) pemujaan tempat suci di Segara.

\section{Pemujaan Dewa-Dewa Lokal}

Tradisi Hindu sangat identik dengan agama yang memberi ruang untuk berkembangnya kepercayaan dan ritualisme kepada mahluk yang lebih rendah dari Tuhan, seperti para butha, kepercayaan kepada para roh penghuni pohon di setiap pohon besar akan ditemukan tempat pemujaan dan pohon itu sendiri dibungkus kain kotak kotak hitam putih, sungai, danau, laut dan lembah dilaksanakannya berbagai upacara 
danu kertih, segara kertih, wana kertih, dan tempat sejenis. Keyakinan dan pemujaan kepada roh para leluhur yang di-istanakan di masing-masing sanggah atau merajan, semakin memperkaya keunikan agama Hindu bagi pemeluknya.

Pemujaan kepada Dewa-Dewa lokal sesungguhnya telah lama dilakukan oleh lelulur kita, bahkan telah diturunkan secara turun-temurun melaui adat dan tradisi yang diwarisi hingga kini. Istilah dewa dalam bahasa Indonesia berasal dari kata dewa atau daiwa (bahasa Sanskerta), yang berasal dari kata diw (bahasa India-Iran), yang berasal dari kata deiwos atau deywos (bahasa Proto-India-Eropa), yang merupakan turunan dari kata diw atau dyew yang bermakna langit, surga, cahaya, atau bersinar. (Titib, 2001 : 45). Para dewa dipercaya sebagai makhluk yang tak tampak dan tak dapat dijangkau. Mereka hidup di tempat-tempat suci atau tempat-tempat yang jauh dari jangkauan manusia, seperti surga, neraka, di atas langit, di bawah Bumi, di lautan yang dalam, di atas puncak gunung tinggi, di hutan belantara, tetapi dapat berhubungan dengan manusia karena manifestasi atau kekuatan supranaturalnya. Pemujaan Dewa-Dewa lokal di Desa Pedawa meruapakan tradisi yang sudah turun-termurun diwarisi oleh masyarakat Desa Pedawa. Hal ini bisa dilihat dalam kutipan Sesapa yang diucapkan oleh Balian Desa Pedawa dalam muput sebuah acara Samskāra sebagai berikut :

Purun titiang mumbuk nangiang nguntap ngojah ngayat ring Ida Pengakan Pratkasu mangda lédang Ida Pengakan Prataksu rauh kadi mangkin,masurya nyaksi matur piuning inggian ngangganin ngancanin riantuk taler panjak druwé.

Terjemahannya

Bersedia saya memuja memuji memanggil kehadapan Ida Pengakan Prataksu gar bersedia Ida Pengakan Prataksu hadir sekarang memberikan waranungrahanya menyaksikan permohonan pemberitahuan mewakili hamba mu ini. (Sesapa Dane Balian Desa, 12 Mei 2021).

Dari kutipan Sesapa yang di ucapakan oleh Dane Balian Desa Pedawa pada saat pelaksanaan upacara Saṃskāra terlihat beliau menyebutkan nama Ida Pengakan Prataksu sebanyak 2 (dua) kali dalam satu bait Sesapa. Hal ini menandakan bahwa Ida Pengakan Prataksu menjadi Dewa yang sangat penting dipuja dalam setiap pelaksanaan Upacara Samsakara yang dilakukan di Desa Pedawa. Dalam kutipan tersebut Dane Balian Desa melakukan permohonan agar Ida Pengakan Prataksu hadir menyaksiskan kegiatan upacara yang sedang dilaksanakan agar bisa memberikan waranugraha. 
Disamping pengucapan Ida Pengakan Prataksu juga disebutkan oleh Dane Balian dengan sebutan Ida Gede Kemulan yang merupakan satu rangkaian dengan pengucapan dengan nama Ida Pengakan Prataksu seperti kutipan berikut ini :

Nawegang titiang nunas makawinan titiang purun ngocap ngojah ngayat Ida Pengakan Prataksu rauh kadi mangkin mangda ledang Ida Prangkan Prataksu ngewekas nguningang antuk ring Ida Pengakan Prataksu rauh kadi mangkin ring Ida Gede Kemulan sami kasungsung antuk lampuan panjak druwé titiang nunas lugra dwaning wénten panjak I Dewa sané magenah ring pratiwi driki magenah anggén ipun pakubon pagenah pajongkokan indik duké punika taler kadi mangda ledang cokor I Dewa, I Dewa Gede Kemulan Sakti masurya kadi mangkin wantah anggé ipun ngewéntang angén sarining plawan akadendel rauh agencekan wakul daksina sekar petak masuar griyané kukus harum punika anggén ipun lantaran bakti nyanggra rauh ring cokor I Dewa sané wantah kasungsung kasunggi ring kadi mangkin iriki mangda lédang rauh ngupasaksi ring pangrestitian antuk ring ibu pertiwi sané madué gumi iriki nyelang genahé puniki ring ibu pertiwi anggén ipun genah pakubon taler pagenah serahina wengi.

Terjemahannya :

Mohon permakluman sebelumnya saya memohon maaf, karena saya kembali saya memuja memuji memanggil Ida Pengakan Pratksu agar bisa hadir bisa memberikan waranungraha bersama dengan Ida Gede Kemulan semuanya yang kami puja oleh kami, saya memohon ampunan karena hari ini ada hambamu yang tinggal disini di Ibu Pertiwi meminjam tempat dipakai tempat tinggal tempat beristirahat oleh karena itu supaya beliau I Dewa, I Dewa Gede Kemulan Sakti bisa memberikan waranungrahanya sinar sucinya agar bisa dipakai oleh hambamu ini meminta sari melalui sarana plawan akadendel sampai dengan agencekan wakul daksina sekar petak masuar griyané kukus harum yang saya pakai untuk menyambut kedatangan Cokor I Dewa yang kami puja kami muliakan pada saat ini, agar bisa hadir menykasikan permohonan kami kepada ibu pertiwi yang meiliki kuasa terhadap bumi ini, tiang memohon meminjam tempat disini dipakai untuk tempat tinggal setiap hari. (Kutipan Sesapa Dane Balian Desa 21 Mei 2021). 
Dari kutipan tersebut penyebutan Ida Pengakan Pratksu diucapak kembali oleh Dane Balian Desa yang dibarengi dengan istilah penyebutan Ida Gede Kemulan, hal ini kemungkinan ada keterpautan antara Ida Pengakan Pratksu dengan Ida Gede Kemulan. Sesuai dengan kutipan diatas bahwa disamping beliau memanggil Ida Pengakan Pratksu juga memanggil Ida Gede Kemulan untuk bisa menyaksiskan upacara yang dilakukan oleh pretisentana nya. Dane Balian Desa juga menyebutkan sarana yang dipakai untuk menyambut beliau agar beliau mau hadir menyaksikan dan memberikan waranugraha berupa plawan akadendel sampai dengan agencekan wakul daksina sekar petak masuar griyané kukus harum.

Hal ini sejalan dengan Sloka Bhagawadgita XVIII.65 bahwa Manusia berkewajiban untuk selalu dan setiap saat ingat dan memusatkan perhatian kita kepada Tuhan Yang Maha Esa. Dalam kitab suci Bhagawadgita XVIII.65 secara tegas menyatakan bahwa :

$$
\begin{aligned}
& \text { Man-mana bhava mad-bhakto, } \\
& \text { mad-yaji mam namaskuru, } \\
& \text { mam evaisyasi satyam te, } \\
& \text { pratijane priyo si me }
\end{aligned}
$$

Terjemahannya:

Berpikirlah tentang Aku senantiasa jadilah penyembah-Ku, bersembahyang dan berdoa kepada-Ku, dengan demikian, pasti engkau datang kepada-Ku, Aku berjanji demikian kepadamu, karena engkau Aku sangat kasihi. (Mantik, 2009:554-555).

Pemahaman terhadap Kutipan sloka diatas yaitu sembahyang dan berdoa mesti senantiasa kita lakukan karena Tuhan Yang Maha Esa menegaskan bahwa dengan senantiasa berpikir tentang-Nya, mengingat-Nya, bersembahyang dan berdoa kepada Nya, Tuhan Yang Maha Esa akan membukakan pintu hati-Nya dan kita datang kepada Nya. Alasan lebih jauh mengapa kita perlu memanjatkan doa adalah dalam rangka proses membiasakan diri (abhyasa) guna mendekatkan diri kepada Tuhan Yang Maha Esa. Mendekatkan diri kepada-Nya dengan membiasakan diri, akan mudah dilakukan bila kita telah memiliki keiklasan (tyaga) dan tidak terikat terhadap terhadap obyek keduniawian (vairagya) mensyukuri karunia-Nya (santosa) dan keseimbangan lahir dan batin dalam suka dan duka (sthitaprajna). Dengan membiasakan diri berpikir tentangNya, memanjatkan doa kepada-Nya di setiap saat, maka melalui doa kita ini, kita akan 
bebas dari segala penderitaan dan pikiran-pikiran negative yang menjerumuskan diri kita dan orang lain. Di mana nama-Nya disebutkan, disana Tuhan Yang Maha Esa hadir dan menganugrahkan kasih dan kebahagiaan.

Demikian pula memanjatkan doa, memohon keselamatan, kerahayuan dan pengampunan dapat dilaksanakan kapan saja, di mana saja dan dalam situasi apapun juga contohnya adalah doa sehari-hari baik yang bersifat rutin maupun insidental dalam ajaran agama Hindu (Titib, 2009:62-64). Mantra seperti energi atom yakni suatu tenaga yang bertindak sesuai dengan rasa bakti seseorang yang mempergunakannya. Sabda adalah Brahman, karena itu Ia menjadi penyebab Brāhmanda (Svami Rama: 1984:24). Khanna (2003:21) menyatakan hubungan mantra dan yantra dengan manifestasi mental energi sebagai berikut: Mantra-mantra,suku kata Sanskerta yang tertulis pada yantra, sejatinya merupakan perwujudan pikiran yang merepresentasikan keillahian atau kekuatan kosmik, yang menggunakan pengaruh mereka dengan getaran suara (Suasthi \& Suadnyana, 2020).

\section{Pemujaan Tempat Suci Di Desa Pedawa}

Secara umum tempat suci umat Hindu adalah Pura dimana fungsinya adalah sebagai tempat untuk memuja Hyang Widhi, para Dewata, disamping itu pura juga memiliki fungsi sebagai tempat untuk memuja Bhatara yaitu roh yang lebih suci. Fungsi Pura dapat diperinci lebih jauh berdasarkan ciri (kekhasan) yang antara laindapat diketahui atas dasar adanya kelompok masyarakat kedalam berbagai jenis ikatan seperti : ikatan sosial, politik, ekonomi, genealogis (garis kelahiran). Ikatan wilayah tempat tinggal (teritorial), ikatan pengakuan atas jasa seseorang guru suci (Dang Hyang Guru), ikatan politik dimasa yang silam antara lain berdasarkan kepentingan penguasa dalam usaha menyatukan masyarakat dalam suatu wilayah kekuasaan. (Titib, 2001 : 95-96).

Pemujaan di Desa Pedawa dalam pelaksanaan upacara Saṃkāra dilakukan menggunakan Sesapa yang menggunakan bahasa Bali dialek Pedawa. Dalam proses pemujaannya, Balian Desa melakukan pemujaan kepada Dewa-Dewa lokal dan juga melakukan pemujaan tempat-tempat yang dianggap suci oleh Masyarakat Desa Pedawa seperti kepada yang berstanda Gunung Sari Pedawa, Di Kamulan Bingin, Telaga Waja Pengempelan. Tempat-tempat yang disebutkan diatas disebutkan beberapa kali ketika Dane Balian Desa melakukan pemujaan pada saat pelaksanaan upacara Saṃskāra. 
Berikut beberapa petikan Sesapa yang menujunkan penyebutan Gunung Sari Pedawa, Di Kamulan Bingin, Telaga Waja Pengempelan sebagai berikut :

Nguningang kadi mangda ledang rauh taler antuk mecantuk rai iring titiang Ida raka Rai Ida Hyang sané kasungsung panjak druwé ring Gunung Sari Pedawa antuk panjak druwené nunas amerta sari antuk pangupa jiwa saking iriki antuk genah ring sajebag Buleleng. Nike pengabtian ngewéntenang ngrastitiang riantuk inggian patut ring inggian sasih kesanga. Naler naweg titiang lugra ring cokor sané patut inggian sané malinggih ring Gunung Sari Pedawa ring Pamulungan Agung minakadi ring Kemulan Penyarikan Pangijeng Bukit Anyar Embang Labuan Aji Antap Sari Dur Sari Ratu Jagat Ularan.

Terjemahannya :

Memberitahukan seperti sekarang supaya bersedia bisa hadir untuk bertemu saya iringi Ida Raka Rai Ida Hyang yang dipuja oleh hambamu di Gunung Sari Pedawa olih hambamu meminta kesejahteraan untuk penghidupan dari sini untuk seluruh wilayah Buleleng. Itu harapan mengadakan permohonan hal ini dikerenakan sasih kesanga. Begitu pula saya momohon permakluman kepada cokor I Dewa yang patut yang berstana di Gunung Sari Pedawa di Pamulungan Agung seperti ring Kemulan Penyarikan Pangijeng Bukit Anyar, Embang Labuan Aji Antap Sari Ratu Jagat Ularan. (Sesapa Dane Balian, 21 Mei 2021).

Dari kutipan diatas terlihat bahwa ada pemujaan yang ditunjukan pada tempattempat yang dianggap suci oleh masyarakat Pedawa seperti Gunung Sari Pedawa yang merupakan nama lain Desa Pedawa. Pemujaan terhadap gunung di Desa Pedawa sesungguhnya merupakan bagian dari tradisi yang sudah dilakukan secara turun temurun mengingat lokasi dari Desa Pedawa ada didataran tinggi. Pemujaan tempat suci lainnya berupa Sungai atau yang sebut dengan Telaga Waja Pengempelan. tempat ini merupakan sebuah tempat yang berada di Desa Pedawa yang diyakini sebagai tempat nunas Pengklukatan atau membersihkan diri. Berikut adalah kutipan pemujaan tempat Telaga Waja Pengempelan sebagai berikut :

Dumogi para keluarga sami sané wénten iriki samian ngemangguhang kerahyaun kerahajengang. Naler sané malinggih ring kemulan telaga waja wénten palinggih sané kasungguh palinggih Telaga Waja Pengempelan.

Terjemahannya 
Semoga keluarga semuanya yang ada disini semuanya memperoleh kebahagiaan keselamatan. Begitu pula yang berstana di Kemulan Telaga Waja ada pelinggih yang disebut Palinggih Telaga Waja Pengempelan. (Sesapa Dane Balian, 21 Mei 2021).

Dari kutipan sesapa tersebut bahwa pemujaan terhadap Gunung, Sungai atau dalam istilah masyarakat Pedawa disebut Telaga Waja Pengempelan yang merupakan sumber air yang diyakini sebagai tempat membersihkan diri. Pemujaan yang dilakukan oleh masyarakat Pedawa yaitu memuja Sungai dan Gunung sejalan dengan konsep Hindu bahwa pemujaan Rgveda VI. 6.28 dan Rgveda 11. 35.3 sebagai berikut :

Di tempat-tempat yang tergolong hening, digunung-gunung, pada pertemuan dua sungai (campuhan), di sanalah para maharsi mendapatkan inspirasi (pikiran) yang jernih. (Rgveda VI. 6.28).

Sejumlah besar air, bersama dengan air-air yang lainnya berkumpul menjadi sungai yang mengalir bersama-sama menuju ke laut (penampungan). Air yang murni, baik dari mata airmaupun taut, mempunyai kekuatan yang menyucikan diri. (Rgveda 11. 35.3).

Lebih jauh di dalam kitab Tantra Sarasamuscaya dinyatakan:

Para dewa tidak hanya berkenan untuk turun dan tinggal di Tirtha (Parirthan), di tepi sungai, dan danau, tetapi juga di tepi pantai. pertemuan dua atau lebih sungai-sungai. dan kuala (muara sungai), di puncak-puncak gunung atau bukitbttkit, di lereng-lereng pegunungan, di hutan, di semak belukar dan kebun atau taman-taman, dekat tempat-tempat yang dirahmati atau pertapaan, di desa-desa, kota-kota dan di tempat-tempat lain yang membahagiakan (I. I .28).

Kepercayaan masyarakat Bali yang beragama Hindu hampir semua puncak pegunungan dan bukit-bukit di Bali juga diyakini sebagai sthana para dewata, bahkan digambarkan sebagai padmadala, kelopak daun bunga teratai yang menurut kitab Wrhaspati Tattwa merupakan sthana Sang Hyang Sadasiva. Kini tempat-tempat yang indah dan menawan itu, tidak saja menjadi kesukaan para dewa untuk turun ke bumi.

\section{Pemujaan Tempat Suci di Hulu Duwurin Capah}

Istilah Duwurin Capah adalah istilah sebutan tempat suci yang berada di kawasan Gunung Lesung, Gunung Sanghyang dan sekitar Kawasan Danau Tamblingan dan Danau Buyan. Bagi sebagian masyarakat di Buleleng kepercayaan terhadap 
peradaban Tamblingan Pada masa Bali Kuno masih sangat eksis dalam pelaksanaan ritual keagamaan yang mengarah pada pemujaan di Duwurin Capah. Termasuk Desa Pedawa merupakan desa Bali Aga yang terkena pengaruh kekuasaan Tamblingan masa Bali Kuno hal ini dapat dicermati dari Sesapa yang diucapkan oleh Balian Desa Pedawa sebagai berikut :

Wus pahit gaduh Rambut Siwi Gunung Raung makasami antuk ayat titiang kading mangkin déning titiang banget nunas nglungsur kalédengan ngupasaksi mangda nénten kadi banget pangrastitin ipun sangkaning wénten mapitandruh Ida Dang Kayang sané sané karajegang ring Gunung Sari Pedawa, naler sané malinggih ring Kemulan Labuan Aji Tengahi Segara, Segara Gedong rahuin ring Hulu Duwurin Capah, Ulun Danu Tamblingan, Dalem Naga Loka, Sang Hyang Kangin, Dangin Capah taler ring Pengukusan.

Terjemahannya

Wus Pahit Gaduh Rambut Siwi Gunung Raung semuanya saya puja pada saat ini, karana saya sangat memohon meminta kesediaan menyaksikan permohonan beliau Ida Dang Kayang yang di stanakan di Gung Sari Pedawa, begitupula yang berstana di Kemulan Labuan Aji Tengahi Segara, Segara Gedong rahuin ring Hulu Duwurin Capah, Ulun Danu Tamblingan, Dalem Naga Loka, Sang Hyang Kangin, Dangin Capah taler ring Pengukusan. (Sesapa Dane Balian, 21 Mei 2021).

Dari kutipan Sesapa Balian Desa Pedawa tersebut dapat dicermati bahwa ada pemujaan yang dilakukan untuk Bhatara-Bhatari yang ada di Hulu Duwurin Capah yang meliputi Ulun Danu Tamblingan, Dalem Naga Loka, Sang Hyang Kangin, Dangin Capah taler ring Pengukusan. Semua nama-nama pura yang disebutkan merupakan pura yang ada di Kawasan Dalem Tamblingan yang hingga kini di sungsung oleh Catur Desa Dalem Tamblingan yang terdiri dari Desa Gobleg, Desa Munduk, Desa Gesing dan Desa Umajero. Hal ini diperkuat dengan hasil wawancara dengan Putu Ardana yang merupakan salah satu tokoh di Dalem Tamblingan, berikut adalah petikan wawancaranya :

Istilah Hulu Duwurin Capah memang sangat lumbrah untuk penyebutan namanama Pura yang ada di seputaran Kawasan Dalem Tamblingan yang meliputi Gunung Lesung Gunung Sang Hyang, Kawasan Danau Tamblingan dan Kawasan Danau Buyan. Pura-pura yang ada di seputaran itulah yang bisa 
dikategorikan sebagai Pura yang berada di Hulu Duwurin Capah. (Wawancara Jro Putu Ardana, 12 Juni 2021).

Dari petikan wawancara tersebut jelas bahwa yang dimaksudkan dengan Hulu Duwurin Capah adalah Kawasan yang berada di Dalem Tamblingan. Tempat-tempat yang disebutkan dalam sesapa oleh Dane Balian Desa merupakan nama Pura yang ada di Kawasan Tamblingan yang meliputi :

a. Pura Ulun Danu Tamblingan merupakan hulu dari danau Tamblingan terletak di sisi utara danau. Pada halaman utama terdapat palinggih meru beratap tiga tingkat, didedikasikan kepada dewata penguasa danau.

b. Tirtha Mangening merupakan pura yang terdapat mata air pada jurang terjal dan sulit dijangkau. Lokasinya tidak jauh dari Pura Ulun Danu Tamblingan. Mata air yang sangat disucikan dan sangat penting di dalam sistem ritus masyarakat Catur Desa Tamblingan, khusus upacara yang berkaitan dengan dewa yadnya yang lebih besar, baik yang dilakukan pada pura umum maupun secara kolektif pada masing-masing keluarga. Kehadiran tirtha mangening diyakini dapat mensukseskan dan menghantar persembahan mereka kepada para dewa.

c. Dalem Tamblingan merupakan pura yang terletak di tepi timur danau Tamblingan. Pemujaan diarahkan pada bangunan induk berupa meru tumpang solas. Di sisi kiri dari meru terdapat bale kecil yang di dalamnya terdapat sebuah arca kuna. Pada halaman itu juga terdapat batu-batu alam tinggalan dari kebudayaan masa lalu yang sempat ada di sekitar tempat ini. Keberadaannya sampai saat ini masih sangat disakralkan dan difungsikan sebagai media pemujaan kepada para dewata. Oleh masyarakat setempat, beberapa batu alam yang khusus berlubang dan diatas lubang diletakkan batu lonjong yang lebih kecil disebut Celak Kontong Lugeng Luwih. Celak kontong merupakan batu yang bulat lonjong. Batu alam yang berlubang yang menjadi landasan batu lonjong disebut lugeng luwih. Kesatuan Celak kontong lugeng luwih sebagai media pemujaan, merupakan wujud abstraksi pertemuan (kopulasi) genital laki dan permpuan. Dalam kebudayaan masyarakat yang lebih tradisional di beberapa belahan dunia dan tentunya bagi masyarakat Hindu Bali di beberapa tempat di Bali, artefak seperti ini dijadikan media pemujaan dalam usaha memohon kesuburan bagi alam. 
d. Pura Endek merupakan tempat sakral di tengah hutan tepi timur Danau Tamblingan. Dalam pura ini terdapat onggokan batu alam yang dikeramatkan, masing-masing palinggih berupa batu alam dan beberapa jenis tumbuhan masih dilestarikan. Terdapat bangunan gedong sebagai tempat pemujaan utama. Gedong ini juga dijadikan media pemujaan oleh beberapa masyarakat Tionghoa di Bali. Ciri budaya Tionghua pun dibangun di bagian depan sebelah kiri bagunan utama berupa pagoda tempat pembakaran uang kertas Cina. Terkadang hari-hari tertentu orang-orang Tionghua datang bersembahyang. Beberapa di antara mereka mengaku bahwa leluhur mereka pernah hidup di Pura Endek ini. Dengan demikian, pura ini menunjukkan wujud pluralisme pemujaan di kawasan danau Tamblingan. Pura Endek khususnya dalam struktur keyakinan masyarakat Catur Desa menjadi pura yang sangat penting. Hal tersebut ditunjukkan dengan adanya palinggih pasimpangan Pura Endek di Pura Pemulung Agung Gobleg. Pada tahun 2002 di areal Pura Endek sempat ditemukan prasasti tembaga, ketika masyarakat bergotong-royong dalam rangka perluasan areal pura. Tiba-tiba cangkul dari seorang warga terantuk batu yang di bawahnya terdapat guci berwarna coklat. Di dalam guci tersimpan beberapa lempeng tembaga bertuliskan aksara Bali Kuna dan Jawa Kuna.

e. Pura Gubung merupakan Tempat suci yang terdapat tepi selatan Danau Tamblingan merupakan komplek pura besar. Di dalamnya terdapat menaramenara meru yang beratap menjulang tinggi yang dijadikan pemujaan oleh karma subak di Buleleng dan Tabanan khususnya.

f. Sangyang Kauh adalah nama tempat suci yang terdapat di depan Pura Gubug. Juga menjadi pura yang diperuntukkan oleh krama subak untuk memohon kesuburan pertanian.

g. Pura Penimbangan merupakan tempat suci yang sangat sederhana, dibatasi oleh tembok keliling. Pada bagian tengahnya terdapat sebuah batu alam besar yang bentuknya seperti meja. Kemungkinan pada jaman dahulu dijadikan dolmen.

h. Pura Embang merupakan Tempat suci yang sangat sederhana dan penuh dengan nuansa alami yang terbuat dari papan-papan batu. Tampak bangunan suci ini berupa tahta batu yang merupakan bukti-bukti tinggalan kebudayaan prasejarah. Akan tetapi saat ini juga dimanfaatkan oleh masyarakat Hindu sebagai tempat pemujaan. Tradisi prasejarah berlanjut di Bali sangatlah kental terutama lebih 
banyak ditemukan pada daerah pegunungan di Bali. Pemanfaatan sumber daya alam seperti ini adalah wujud arif masyarakat yang ramah lingkungan. Mereka dengan tidak susah payah menggali batu padas, namun mengambil batu-batu yang ada dipermukaan tanah. Mengingat, batu-batu alam tersebut banyak sekali terdapat di permukaan di sekitar danau Tamblingan. Kini tempat suci ini difungsikan oleh masyarakat sekitar sebagai tempat untuk memohon kesuburan, utamanya yang berhubungan dengan perkebunan.

i. Catur Lepus Tempat suci yang dijadikan tempat pemujaan oleh komunitas masyarakat yang mengataskan diri sebagai warih Pande di Bali. Pura yang baru dibangun dengan megah, yang sebelumnya terdapat onggokan palung batu kuna. Tinggalan budaya masa lalu itu sejauh ini diduga sebagai tinggalan masyarakat Pande Tamblingan yang pernah bermukim di tepian Danau Tamblingan. Dalam prasasti Tamblingan disebutkan bahwa ada sekelompok pengerajin logam yang pernah hidup di kawasan itu dan diperkuat juga dari hasil penelitian Balai Arkeologi Denpasar, bahwa terdapat bukti-bukti kebudayaan masyarakat pengerajin logam pernah berkembang di sekitar danau Tamblingan dengan temuan bukti berupa lelehan besi, alat penjepit, alat tuang logam.

j. Pura Pucak merupakan pura yang terdapat diatas gunung lesung yang hanya terdiri dari satu pelinggih sejenis gedong. Biasanya orang yang tangkil kesana sekalian melakukan persembahyangan di Pura Goa Naga Loka.

k. Pura Goa Naga Loka merupakan pura yang ada digunung Lesung yang terdapat sebuah lubang yang sangat dalam atau yang lumbrah orang menyebutnya goa vertical. Menurut kepercayaan sebagaian orang bahwa goa vertical tersebut tembus di Pura Labuan Aji yang berada di Pantai Pesisir Pantai Utara.

Dari 11 (Sebelas) pura yang ada di Kawasan Dalem Tamblingan tersebut ada beberapa yang dipuja oleh masyarakat pedawa meliputi Ulun Danu Tamblingan, Dalem Naga Loka, Sang Hyang Kangin, Dangin Capah taler ring Pengukusan. Semua Pura tersebut merupakan bagian dari gugus sebelas pura yang ada di Hulu Duwurin Capah Dalem Tamblingan. Dari uraian tersebut jelas terlihat bahwa ada hubungan yang sangat deka tantara sistem religi masyarakat Desa Pedawa dengan Catur Desa Dalem Tamblingan yang tepat berada di atas Desa Pedawa. Hal lain yang mendukung bahwa ada kekerabatan yang sangat dekat antara Masyarakat Desa Pedawa dengan Catur Desa Dalem Tamblingan dapat dilihat dari kutipan sesapa yang diucapkan oleh Dane Balian 
Desa sebagai berikut :

Nike pengabtian ngewéntenang ngrastitiang naler naweg titiang lugra ring cokor sané patut inggian sané malinggih ring Gunung Sari Pedawa ring Pamulungan Agung minakadi ring Kemulan Penyarikan Pangijeng Bukit Anyar Embang Labuan Aji Antap Sari Dur Sari Ratu Jagat Ularan, déning I Ratu Cokor I Dewa kadi antuk ayat titiang rauh ngupasaksiang antuk makta genah makta linggihan anggéna genah pakubon iriki.

Terjemahannya

Itu harapan mengadakan pemujaan karena juga saya meminta maaf kehadapan Ida Cokor I Dewa yang patut, yang berstanda di Gunung Sari Pedawa begitu pula di Pamulungan Agung, juga Kemulan Penyarikan Pangijeng Bukit Anyar Embang Labuan Aji Antap Sari Dur Sari Ratu Jagat Ularan, juga I Ratu Cokor I Dewa untuk saya memohon untuk datang menyaksikan untuk tempat dan stana yang dipakau tempat disini. (Sesapa Dane Balian Desa 21 Mei 2021).

Dari kutipan sesapa tersebut bahwa Dane Balian Desa melakukan pemujaan kepada Pemulungan Agung yang teradapat di Desa Gobleg. Bahkan pada upacara ngangkid selalu nunas tirta ke Pura Pemulungan Agung sekalgus meminta pentujuk kepada Dane Gusti Agung yang merupakan Panglingsir Catur Dalem Tamblingan di Desa Gobleg.

\section{Pemujaan Tempat Suci Di Segara}

Pemujaan Tempat Suci di Segara juga dilakukan oleh Masyarakat Desa Pedawa, hal ini dapat dilihat dari pelaksanaan upacara Saṃskāra yang ada di Desa Pedawa pasti didahului dengan nunas tirta di Pura Labuan Aji merupakan Pura yang ada di Pesisir Pantai Bali Utara. Dalam kontek Yos yaitu sistem kelompok kekerabatan yang ada di Desa Pedawa dimana terdapat keluarga inti yang terdiri dari seorang suami, seorang istri, dan anak-anak mereka yang belum kawin. Di Desa Pedawa terdapat empat belas (14) macam Yos diantaranya (1) Yos Gunung Agung; (2) Yos Kemulan Bingin; (3) Yos Penyarikan; (4) Yos Bukit Anyar; (5) Yos Labuan Aji; (6) Yos Embang; (7) Yos Munduk Duwur; (8) Yos Kemulan Telaga Waja; (9) Yos Pengempelan; (10) Yos Rambut Siwi; (11) Yos Gadung Gaduh; (12) Yos Muspait; (13) Yos Kemulan Munduk Madeg-Batan Kadap; (14) Yos Batur Mekasa. 
Dari 14 (empat belas) Yos tersebut ada salah satu Yos yang berkaitan dengan Labuan Aji yaitu Yos Labuan Aji dimana Yos ini mempunyai status dan peran sebagai kelian adat. Jika dilihat dari Yos yang lain sesungguhnya tidak semua penyungsung Yos memiliki status dan peran di dalam upacara, tetapi hanya beberapa anggota masyarakat saja yang memiliki status dan peran dalam suatu upacara.masyarakat yang menyungsung Yos Gunung Agung yang mempunyai status dan peran sebagai balian desa. Balian desa tersebut harus sesuai dengan keturunan.Balian desa adalah seorang yang memiliki wewenang atau kewajiban sebagai pemuput segala upacara dari adat. Kewajiban dari seorang balian desa yaitu sebagai pemuput upacara dari adat atau upacara di pura yang dibantu oleh premas. Selain status dan peran dari penyungsung Yos gunung, juga terdapat status dan peran dari masyarakat yang menyungsung Yos Labuan Aji. Premas adalah seseorang yang mengempon pura dadia atau sama dengan pemangku pura dadia. Premas memiliki kewajiban yang sama dengan pemangku yaitu membantu Ulu Desa mepinunas atau nganteb balianyang biasa disebut moncol artinya setiap langkah berkaitan dengan parahyangan.

Data yang lain yang menunjukan keterikatan antara Masyarakat Pedawa dengan Pura Labuan Aji bisa disimak dari Sesapa Dane Balian Desa yang memuja Pura Labuan Aji sebagai salah satu tempat yang diyakini memiliki kekuatan magis untuk bisa memberikan kesejahteraan bagi masyarakat Desa Pedawa. Berikut adalah kutipan Sesapa Dane Balian Desa yang memuja Pura Labuan Aji :

Nike pengabtian ngewéntenang ngrastitiang naler naweg titiang lugra ring cokor sané patut inggian sané malinggih ring Gunung Sari Pedawa ring Pamulungan Agung minakadi ring Kemulan Penyarikan Pangijeng Bukit Anyar Embang Labuan Aji Antap Sari Dur Sari Ratu Jagat Ularan, déning I Ratu Cokor I Dewa kadi antuk ayat titiang rauh ngupasaksiang antuk makta genah makta linggihan anggéna genah pakubon iriki.

Terjemahannya

Itu harapan mengadakan pemujaan karena juga saya meminta maaf kehadapan Ida Cokor I Dewa yang patut, yang berstanda di Gunung Sari Pedawa begitu pula di Pamulungan Agung, juga Kemulan Penyarikan Pangijeng Bukit Anyar Embang Labuan Aji Antap Sari Dur Sari Ratu Jagat Ularan, juga I Ratu Cokor I Dewa untuk saya memohon untuk datang menyaksikan untuk tempat dan stana yang dipakau tempat disini. (Sesapa Dane Balian Desa 21 Mei 2021). 
Kuipan tersebut jelas menunjukan bahwa adanya keterikatan antara Desa Pedewa dengan Pura Labuan Aji, baik dari sistem sosial yang tergabung dalam Yos juga dalam sistem religi dimana selalu melakukan pemujaan disetiap pelaksanaan Samsakara di Desa Pedawa.

\section{Kesimpulan}

Pemujaan Dewa-Dewa Lokal dalam pelaksanaan Samskāra di Desa Pedawa dapat dibedakan menjadikan 4 yaitu (1) pemujaan yang khusus ditunjukan untuk dewadewa lokal yaitu pemujaan kepada Dewa-Dewa yang diyakini oleh masyarakat Pedawa memberikan keselamatan seperti sebutan Ida Pengakan Prataksu, Ida Gede Kemulan, Rai Ida Hyang dan Sebutan lainnya yang tidak lumbarah disebutkan oleh masyarakat Hindu pada umumnya (b) pemujaan khusus untuk tempat di Desa Pedawa seperti Gunung Sari Pedawa, Di Kamulan Bingin, Telaga Waja Pengempelan dan tempat lainnya di Desa Pedawa (c) pemujaan tempat suci di Duurin Capah yaitu pemujaan kepada pura pura yang ada di Kawasan Tamblingan dan Buyan atau yang dikenal dengan Catur Desa Dalem Tamblingan seperti Pura Ulun Danu Tamblingan, Dalem Naga Loka, Sang Hyang Kangin, Dangin Capah taler ring Pengukusan. (d) pemujaan tempat suci di Segara yaitu pemujaan Pura Labuan Aji yang diyakini oleh masyarakat Duwuran Capah sebagai Pura yang sangat penting yang ada di pesisir Pantai Utara Bali.

\section{Daftar Pustaka}

Donder. I K. (2006). Brahmavidya: teologi kasih semesta \& kritik terhadap epistemologi teologi, klaim kebenaran, program misi, komparasi teologi, dan konversi. Paramitha : Surabaya.

Febriani, A., Dkk.(2020).Yos Sebagai Pengintegrasian Masyarakat Desa Pedawa. Humanis: Journal of Arts and Humanities Vol 24.3 Agustus 2020: 297-305.

Geriya. I.W. (1991). Peranan Agama Hindu dalam Transformasi Budaya. Denpasar : Institut Hindu Dharma.

Hooykas, C.(1951). Penyedar Sastra. Jakarta: J.B.Wolters.

Koran Bali Express Jawa Post Group Terbitan 26 Maret 2021 
Lanus, S. (2014). Puja Tri Sandhya: Indian Mantras Recomposed and Standardised in Bali. Oxford University Press and The Oxford Centre for Hindu Studies. USA.

Mayuko, H. (2015). Bentuk Hormat Dialek Bahasa Bali Aga dalam Konteks Agama. Jurnal Masyarakat Linguistik Indonesia ISSN : 0215-4846. Jakarta.

Moleong, L.J. (2013). Metodologi Penelitian Kualitatif. Bandung: PT Remaja Rosdakarya.

Pudja, G. (2005). Bhagawad Gita (Pancama Veda). Surabaya: Paramita.

Suasthi, I. G. A., \& Suadnyana, I. B. P. E. (2020). Membangun Karakter "Genius" Anak Tetap Belajar Dari Rumah Selama Pandemi Covid-19 Pada Sekolah Suta Dharma Ubud Gianyar. Cetta: Jurnal Ilmu Pendidikan, 3(3), 431-452.

Sukrata, I W. (1995). Tinjauan Upacara Ngangkid Sebagai Pelaksanaan Pitra Yadnya di Desa Adat Pedawa Kecamatan Banjar Kabupaten Buleleng. Singaraja. Sekolah Tinggi Keguruan Dan Ilmu Pendidikan.

Suwatno. E. (2004). Bentuk dan Isi Mantra. Jurnal Humaniora Volume 16, No.3, Oktober $2004: 321-331$.

Titib, I M. (1996). Veda Sabda Suci Pedoman Praktis Kehidupan. Surabaya: Paramita.

Titib, I M. (2009). Tri Sandhya Sembahyang dan Berdoa. Surabaya: Paramita

Titib. I M. (2003). Teologi dan Simbol-Simbol dalam Agama Hindu. Surabaya : Paramitha.

Titib. I M. (2005). Kamus Istilah Agama Hindu. Denpasar: Kantor Wilayah Departemen Agama Provinsi Bali

Informan : Nyoman Kalam (Pan Karpini) (Balian Desa) 